\title{
Inhibitory effect of curcumin on angiogenesis in ectopic endometrium of rats with experimental endometriosis
}

\author{
YING ZHANG $^{1 *}$, HONG CAO $^{2,3^{*}}$, YUE-YUE HU ${ }^{1}$, HUA WANG $^{1}$ and CHANG-JUN ZHANG ${ }^{1}$ \\ ${ }^{1}$ Reproductive Medical Center, The Affiliated People's Hospital of Hubei Medical University, Shiyan 442000, Hubei; \\ ${ }^{2}$ Zhongnan Hospital of Wuhan University, Wuhan 430071, Hubei; ${ }^{3}$ Department of Orthopedic Surgery, \\ The Affiliated People's Hospital of Hubei Medical University, Shiyan 442000, Hubei, P.R. China
}

Received August 11,2010; Accepted October 8, 2010

DOI: $10.3892 / \mathrm{ijmm} .2010 .552$

\begin{abstract}
The aim of this study was to observe the inhibitory effect of curcumin on endometriosis (EMS) and to determine its influence on vascular endothelial growth factor (VEGF) and microvessel density (MVD) in eutopic and ectopic endometrium of experimental rats, thus exploring the pathogenesis of EMS offering more experimental evidence for the clinical use of curcumin. Forty-eight female virgin rats were subjected to autotransplantation of endometrium during the estrus stage. After four weeks, 8 rats were randomly sacrificed to confirm that the rat model was successful. The remaining rats were randomly divided into four groups. Three groups were intragastrically administered curcumin $(50,100$ and $150 \mathrm{mg} / \mathrm{kg})$, and the model group was intragastrically administered vehicle alone. All rats were treated daily for four continuous weeks and examined by histology and immunohistochemical staining for MVD of eutopic and ectopic endometrium. Our results revealed that the cubic capacity of focal tissue in gross appearance was high in the model group and dose-dependently diminished after treatment with curcumin $(\mathrm{P}<0.05)$. There was an increase in MVD and VEGF in the ectopic endometrium, which was decreased significantly after treatment with curcumin $(\mathrm{P}<0.05)$; the effects being dose-dependent. The correlation between MVD and VEGF was positive. In conclusion, heterogeneity was found to exist between eutopic and ectopic endometrium due to differences noted in MVD and the expression of VEGF between the eutopic and ectopic endometrium in the model group. Curcumin decreased the quantity of microvessels and VEGF protein expression in the heterotopic endometrium of rats with EMS.
\end{abstract}

Correspondence to: Dr Chang-Jun Zhang, Reproductive Medical Center, The Affiliated People's Hospital of Hubei Medical University, Shiyan 442000, Hubei, P.R. China

E-mail: caohong12345@sohu.com

${ }^{*}$ Contributed equally

Key words: endometriosis, angiogenesis, vascular endothelial growth factor, microvessel density

\section{Introduction}

Endometriosis (EMS) is defined by the presence of functional endometrial tissue outside the uterus, where it is normally located. EMS affects an estimated 10 to $15 \%$ of all premenopausal women (1), and infertility in women with endometriosis is approximately $30 \%(2,3)$. The etiology and pathogenesis of EMS is still unclear. Angiogenesis represents a crucial step in the pathogenesis of EMS since endometriotic lesions require neovascularization to establish, proliferate and invade inside the peritoneal cavity. When shed and attached to the peritoneal surface or other body parts, the ectopic endometrial tissue rebuilds itself and the surrounding glands and stroma. Endometrial lesions grow quickly and this growth requires many new blood vessels; therefore, blood vessel formation promotes survival of ectopic endometrial implantation in basic conditions and in EMS (3-8).

Research has revealed that tradition Chinese medicine can inhibit the growth of ectopic endometrial tissues, regulate hormone release, and regulate the expression of estrogen and progesterone receptors $(9,10)$. Curcumin is the main component of turmeric. Studies have found that curcumin can inhibit tumor growth by inhibiting angiogenesis both in vivo and in vitro (11-15). However, the development of endometriosis and the impact of angiogenesis is rarely reported. In the present study, we modified an autologous transplant model of endometriosis in rats and observed the effect of curcumin on angiogenesis and EMS in this model. We also studied the mechanism of the effect of curcumin in the restriction of ectopic endometrial vascular formation.

\section{Materials and methods}

Materials. Curcumin (molecular weight 368.4, purity 99\%) was purchased from Fluka Chemie GmbH (USA). The chemical structural formula of curcumin is shown in Fig. 1. Sodium carboxymethyl cellulose solution $(0.5 \%)$ was donated by the pharmacy of the Affiliated People's Hospital of Yunyang Medical College, China. An immunohistochemical kit for microvascular staining with rabbit anti-mouse CD31 polyclonal antibody was purchased from Biosynthesis Biotechnology Co., Ltd. (China). 3,3'-Diaminobenzidine (DAB) color reagent was purchased from Maxim BioTechnology Development Co., Ltd. (China). Rabbit anti- 3 -actin 
<smiles>COc1cc(/C=C/C(=O)CC(=O)/C=C/c2ccc(O)c(OC)c2)ccc1O</smiles>

Figure 1. Chemical structural formula of curcumin $\left(\mathrm{C}_{21} \mathrm{H}_{20} \mathrm{O}_{6}\right)$.

polyclonal antibody and rabbit polyclonal anti-VEGF antibody were purchased from Santa Cruz Biotechnology (Santa Cruz, CA, USA). Lysis buffer was purchased from Biotechnology Research Institute Beyotime Institute of Biotechnology (China). Goat anti-rabbit IgG was purchased from ImmuClub Labs (Sunnyvale, CA, USA). A electrochemiluminescence (ECL) color kit was purchased from the Pierce Co. (USA). Pre-stained protein marker was purchased from Fermentas Company (Lithuania). Black and white film was purchased from Kodak Company (USA).

Female Wistar rats $(n=68)$ (mean age $60 \pm 5$ days, mean body weight $180 \pm 10 \mathrm{~g}$ ) were provided by the Yunyang Medical Experimental Animal Center. Animals were housed separately under a standard $12 \mathrm{~h}$ light: $12 \mathrm{~h}$ dark cycle. Before the experiment, all rats were maintained for several days to observe their health condition. All of the animal experiments were in accordance with animal ethics standards.

\section{Experimental methods}

Modeling method. Female Wistar rats were evaluated at the same time every day for vaginal smears indicating the estrus cycle. Rats were selected following two or more consecutive normal estrus cycles (vaginal smear as a large number of nuclear-free keratinocytes). The day before modeling, intramuscular estradiol $[0.1 \mathrm{mg} /(\mathrm{kg} \cdot \mathrm{d})]$ was administered to animals determined to be in the estrus cycle.

The EMS animal model developed by Haber et al (15) was modified. Briefly, $10 \%$ intraperitoneal chloral hydrate $(3 \mathrm{ml} / \mathrm{kg})$ was administered as anesthesia. The abdomen was aseptically opened in the middle for surgery. Blunt tweezers were used to find and isolate the right side of the uterus, ligation was performed at both ends, and the middle section of the uterus was cut and quickly placed in a curved plate filled with saline solution. Eye scissors were used to cut along the mesangial area of the uterine tube, which was cut into $4 \times 4 \mathrm{~mm}$ uterine pieces (including muscle), taking care to distinguish between the inside and outside membranes. A tunnel was made between the subcutaneous and abdominal fascia on both sides of the abdominal incision, which segmented the flat uterus into the tunnel at the bottom. This left the intimal surface close to the abdominal muscles. The abdomen was then closed by conventional methods. Beginning the second day after the operation, an intramuscular injection of estradiol $[0.1 \mathrm{mg} /(\mathrm{kg} \cdot \mathrm{d})]$ was administered every four days for a total of three times to promote the growth of the ectopic endometrium.

The modeling method for the sham group was almost the same as the model group, except the middle section of the uterus that was cut out was discarded.

Delivery method. Forty-eight Wistar rats were modeled by the methods described above. Four weeks after modeling,
8 were sacrificed. Pathological findings from the endometrial glands, stroma, or hemosiderin cells confirmed that the modeling was successful. The remaining 40 rats were then randomly divided into 4 groups of 10 each: the model group, a low-dose curcumin group [50 $\mathrm{mg} /(\mathrm{kg} \cdot \mathrm{d})]$, a middle-dose curcumin group $[100 \mathrm{mg} /(\mathrm{kg} \cdot \mathrm{d})]$ and a high-dose curcumin group $[150 \mathrm{mg} /(\mathrm{kg} \cdot \mathrm{d})]$.

The curcumin groups were treated with $0.5 \%$ sodium carboxymethyl cellulose intragastrically in a uniform dubbed $1-\mathrm{ml}$ suspension. The model group, sham operation group and normal group received equal amounts of $0.5 \%$ sodium carboxymethyl cellulose solution intragastrically.

Specimen collection. Animals were sacrificed after 4 weeks of oral treatment. Layer by layer, the abdominal cavity of each group of rats was opened to observe and compare the ectopic endometrial morphology. Eutopic and ectopic endometrium were removed bilaterally. The eutopic endometrium was divided into two sections. One section and one side of the ectopic endometrium were immediately placed into a 1-ml Eppendorf tube, marked, and frozen at $-70^{\circ} \mathrm{C}$ for later use. Another section of eutopic endometrium and the other side of the ectopic endometrium were placed in $10 \%$ formaldehyde solution, fixed, and paraffin-embedded after $48 \mathrm{~h}$. Serial sections $(4 \mu \mathrm{m})$ were collected for H\&E and immunohistochemical staining.

\section{Observed indicators and inspection methods}

Toxicity and quality of life. After modeling and drug administration, the appetite, activity, response to stimuli and changes in body weight of the rats were noted to assess side effects and quality of life. Following sacrifice, each rat was dissected to determine the cause of death.

Ectopic endometrium and size. After modeling, the rat abdomens were palpated 2 times per week to observe the mass and its size. After 4 weeks, rats were sacrificed, and diagnosis was confirmed by pathology by measuring the size of the ectopic tissue (length $\mathrm{x}$ width $\mathrm{x}$ height, in $\mathrm{mm}^{3}$ ). Differences between groups were compared.

Immunohistochemical detection of microvessel density (MVD). Detection of MVD was determined following the instructions provided in the kit. Briefly, the first antibody (CD31 rabbit polyclonal anti-antibody) was diluted 1:200 and incubated overnight at $4^{\circ} \mathrm{C}$. The biotinylated secondary antibody (rabbit anti-mouse) was added, followed by horseradish peroxidase streptavidin working solution, DAB color and hematoxylin for $2 \mathrm{~min}$. A change in color was observed under a microscope.

CD31-positive cells in the cytoplasm appeared as brown particles. CD31 polyclonal antibody-stained endothelial cells, clusters of individual microvascular endothelial cells, red blood cells and the appearance of the lumen were not judged. A thick muscle layer, fibrosis, and a lumen diameter more than eight red blood cells in size were not counted. Low magnification (x100) was used to review the microvascular staining in each section and determine the maximum microvascular staining regions. The five highest microvascular staining regions were selected for high 
Table I. Comparison of the body weight of the rats before and after curcumin treatment.

Body weight before curcumin treatment $(\mathrm{g})$

Body weight after curcumin treatment $(\mathrm{g})$

\begin{tabular}{llc}
\hline Normal group & $200.9 \pm 12.40$ & $204.90 \pm 14.21$ \\
Sham group & $200.0 \pm 20.52$ & $203.40 \pm 18.61$ \\
Model group & $199.0 \pm 16.32$ & $205.13 \pm 13.28$ \\
Curcumin $50 \mathrm{mg} /(\mathrm{kg} \cdot \mathrm{d})$ group & $206.3 \pm 13.48$ & $209.11 \pm 16.16$ \\
Curcumin $100 \mathrm{mg} /(\mathrm{kg} \cdot \mathrm{d})$ group & $205.9 \pm 15.05$ & $209.50 \pm 15.35$ \\
Curcumin $150 \mathrm{mg} /(\mathrm{kg} \cdot \mathrm{d})$ group & $201.1 \pm 18.70$ & $206.33 \pm 19.50$ \\
\hline
\end{tabular}

Values are presented as the mean $\pm \mathrm{SD}$.

Table II. Comparison of the graft (ectopic endometrium) volumes.

\begin{tabular}{lc}
\hline & Graft volume $\left(\mathrm{mm}^{3}\right)$ \\
\hline Model group & $185.08 \pm 152.54$ \\
Curcumin $50 \mathrm{mg} /(\mathrm{kg} \cdot \mathrm{d})$ group & $87.71 \pm 80.23^{\mathrm{a}}$ \\
Curcumin $100 \mathrm{mg} /(\mathrm{kg} \cdot \mathrm{d})$ group & $60.56 \pm 55.21^{\mathrm{a}}$ \\
Curcumin $150 \mathrm{mg}(/ \mathrm{kg} \cdot \mathrm{d})$ group & $31.98 \pm 32.18^{\mathrm{b}}$ \\
\hline${ }^{\mathrm{a} C o m p a r e d ~ w i t h ~ t h e ~ m o d e l ~ g r o u p, ~} \mathrm{P}<0.05 .{ }^{\mathrm{b}}$ Compared with the \\
curcumin $50 \mathrm{mg} /(\mathrm{kg} \cdot \mathrm{d})$ group, $\mathrm{P}<0.05$. Values are presented as the \\
mean $\pm \mathrm{SD}$.
\end{tabular}

magnification (x400) microvessel count, and the average was calculated.

Detection of VEGF protein expression by Western blotting. One hundred milligrams of cryopreserved endometrial tissue was obtained. The protein lysate was added according to quality/volume (w/v, $\mathrm{mg} / \mu \mathrm{l}), 1: 5$, fully homogenized, placed on ice for $30 \mathrm{~min}$, and then centrifuged for $5 \mathrm{~min}$ at $260 \mathrm{x} \mathrm{g}$. Protein concentration was measured with a bicinchoninic acid kit, and a standard curve was drawn. Protein content in each sample was calculated using a standard curve. Proteins were denatured, the sample was added, and electrophoresis was performed. Transmembrane staining imprinted the membrane protein. The blocking solution was discarded, and the first anti-solution (VEGF and B-actin were 1:200 diluted with blocking solution) was added. The shaking bed was set at room temperature and the samples were incubated for $1 \mathrm{~h}$ and then revived again in the refrigerator at $4^{\circ} \mathrm{C}$ overnight. The membrane was washed and the second anti-solution was added (VEGF and B-actin were 1:2000, diluted with TBS-T). Samples were set to shake at room temperature for $1 \mathrm{~h}$. Chemiluminescence and imaging were performed, and a snapshot was captured. The film was scanned and the image saved. Quantity One software analysis determined the optical density of the band. The target band and $\beta$-actin optical density are expressed as a ratio of relative expression of the target protein.
Statistical analysis. Using SPSS 13.0 software, data were analyzed by one-way ANOVA to compare differences between groups. Post hoc $2 \times 2$ analyses were performed by SNK using index correlation between groups for linear correlation analysis. The level of statistical significance was set at $\mathrm{P}<0.05$, and $\mathrm{P}<0.01$ indicated a significant statistical difference.

\section{Results}

Toxicity and quality of life observed. The response to stimuli, activity level, and appetite of each group were similar to the normal group, and the body weight did not change significantly (Table I).

Condition of ectopic endometrium. Ten days after modeling, a small mass (the size of a grain of rice) was felt in the abdomens of the rats. When sacrificed 4 weeks later, 45 rats had palpable masses on both sides, 2 rats had a palpable mass on one side, and 1 rat was not palpable on either side. Ectopic endometria were solid and cystic. The size of the ectopic endometria ranged from $13.7 \times 10.1 \times 9.6 \mathrm{~mm}^{3}$ to $3.1 \times 1.5 \mathrm{x}$ $1.0 \mathrm{~mm}^{3}$. The differences in the volume of the graft in each group had statistical significance $(\mathrm{P}<0.05$; Table II).

Histopathologic observation. After rats were sacrificed, the ectopic endometrium of each rat was found to have exhibited extensive growth, and the volume had increased significantly, showing a small cystic bulge that was bright and full of fluid inside which surface blood vessels could be observed (Fig. 2). When observed using low magnification microscopy, the transplanted material had grown into one or more cavitylike structures, including the cavity surface epithelium, stromal cell membrane and the lamina propria. Gland-like structures in the normal and sham operation groups were similar to those found in the uterus. Upon high powered microscopy, epithelial cells resembled well-grown low columns. Necrosis and inflammatory cell infiltration were noted, and the lamina thickness and maturity were similar to those in the normal mature uterus within which a large number of spindle stromal cells and hemosiderin cell cavity secretions and inflammatory cells existed. After curcumin treatment in the low-dose group, four grafts under the effusion were not fully absorbed, ectopic endometria did not present hyperplasia, 

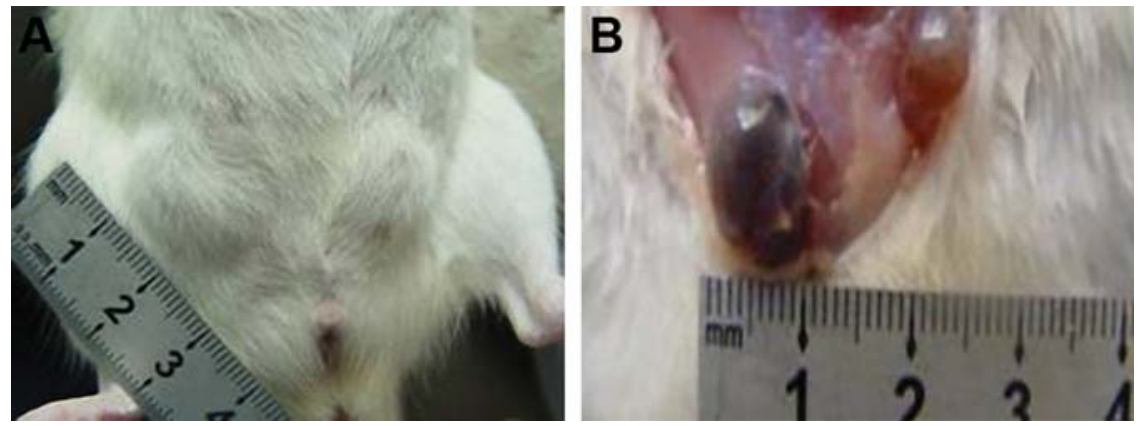

Figure 2. After modeling, a mass is noted in the rat abdomen with the naked eye (A). Upon laparotomy, the growth of the graft volume was found to have increased significantly, showing a small cystic bulge that is bright and full of fluid and through which surface blood vessels were observed (B).
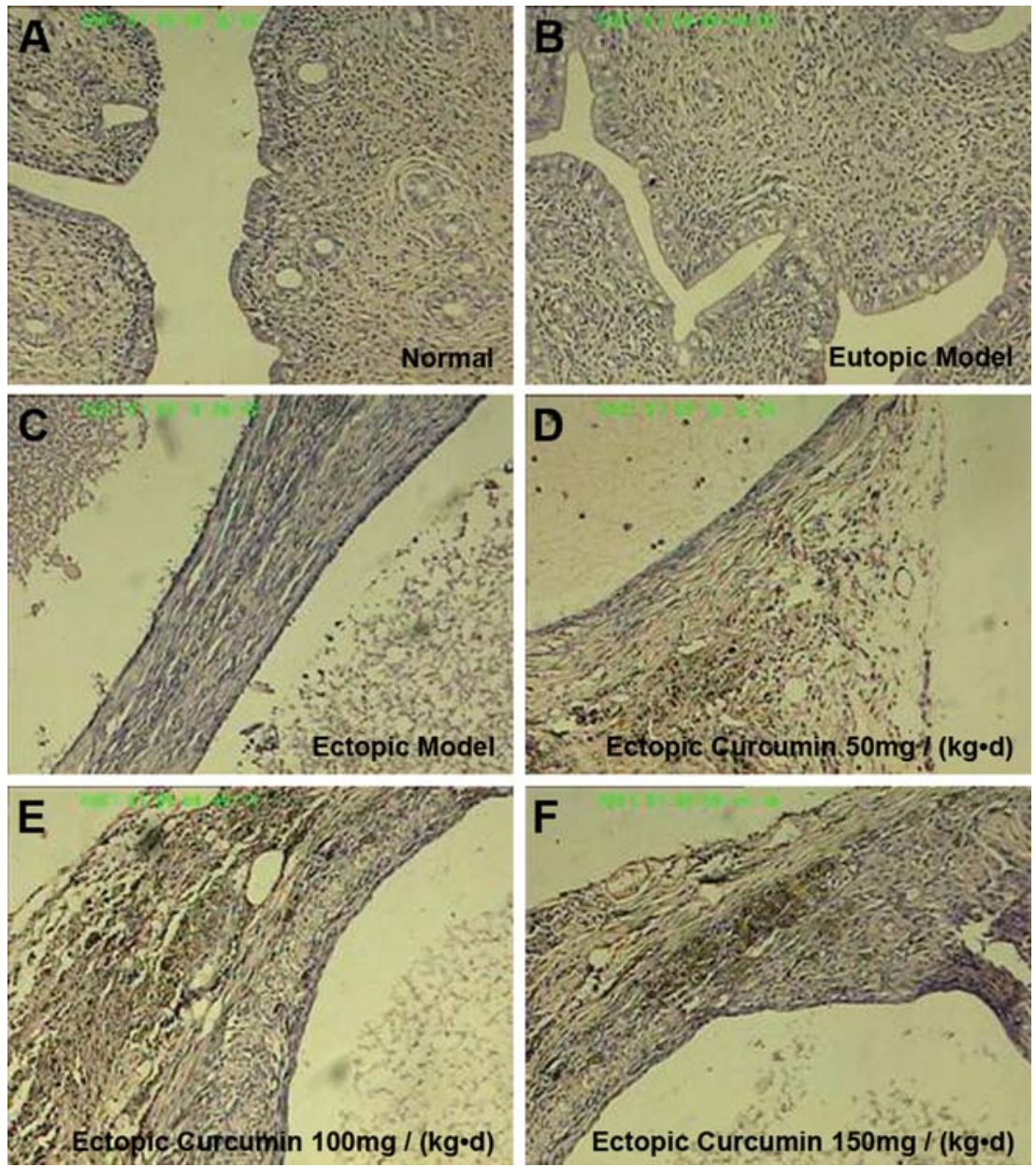

Figure 3. The normal group shows columnar growth of endometrial epithelium and abundant glands in the interstitial tissue (A). The model group exhibits eutopic endometrial glandular epithelial cells that are columnar with more interstitial glands (B). Ectopic tissue of the model group forms two cavity-like structures with inflammatory cell infiltration in the cavity. The interstitial tissue is thin, and fibrosis and the glands and muscle layer disappeared (C). The curcumin $50 \mathrm{mg} /(\mathrm{kg} \bullet \mathrm{d})$ group exhibits no significant ectopic tissue hyperplasia, and the interstitial gland is reduced and narrow (D). The curcumin $100 \mathrm{mg} /(\mathrm{kg} \bullet \mathrm{d})$ group displays ectopic tissue that is sparse and the interstitial tissue has a large number of hemosiderin particles (E). In the curcumin $150 \mathrm{mg} /$ $(\mathrm{kg} \bullet \mathrm{d})$ group the ectopic gland tissue disappeared, and the luminal is narrow, has less secretions and exhibits a shrinking state. (A) Normal group; (B) eutopic endometrium of the model group; (C) ectopic endometrial samples of the model group. (D-F) Ectopic endometrium of the (D) 50, (E) 100, and (F) $150 \mathrm{mg} /$ $(\mathrm{kg} \bullet \mathrm{d})$ curcumin-treated groups. (A-F: H\&E, x100).

glands were reduced and stroma stenosis was present. Two rats in the middle-dose group and 3 rats in the high-dose group had effusion under the grafts that were not fully absorbed. The rest were noted as flat, patchy grafts exhibiting atrophy. Ectopic endometrial glands decreased as the lumen narrowed, cells were sparse, and there were fewer secretions in this shrinking state (Fig. 3).

MVD count of eutopic and ectopic endometrium. The MVD of ectopic endometrium was higher than that in the eutopic 
Table III. MVD values of eutopic and ectopic endometrium in each rat group.

MVD in eutopic endometrium

MVD in ectopic endometrium

\begin{tabular}{lcc}
\hline Normal group & $17.60 \pm 5.85$ & - \\
Sham group & $17.54 \pm 2.35$ & - \\
Model group & $19.93 \pm 4.51$ & $25.51 \pm 8.85$ \\
Curcumin $50 \mathrm{mg} /(\mathrm{kg} \cdot \mathrm{d})$ group & $18.43 \pm 2.96$ & $13.50 \pm 4.17^{\mathrm{a}}$ \\
Curcumin $100 \mathrm{mg} /(\mathrm{kg} \cdot \mathrm{d})$ group & $16.71 \pm 4.15$ & $11.03 \pm 0.85^{\mathrm{a}}$ \\
Curcumin $150 \mathrm{mg} /(\mathrm{kg} \cdot \mathrm{d})$ group & $16.38 \pm 3.47$ & $8.96 \pm 0.59^{\mathrm{a}, \mathrm{b}}$ \\
\hline
\end{tabular}

${ }^{a}$ Compared with the model group, $\mathrm{P}<0.05$; ${ }^{\mathrm{b}}$ compared with the curcumin $50 \mathrm{mg} /(\mathrm{kg} \cdot \mathrm{d})$ group, $\mathrm{P}<0.05$. Values are presented as the mean $\pm \mathrm{SD}$.
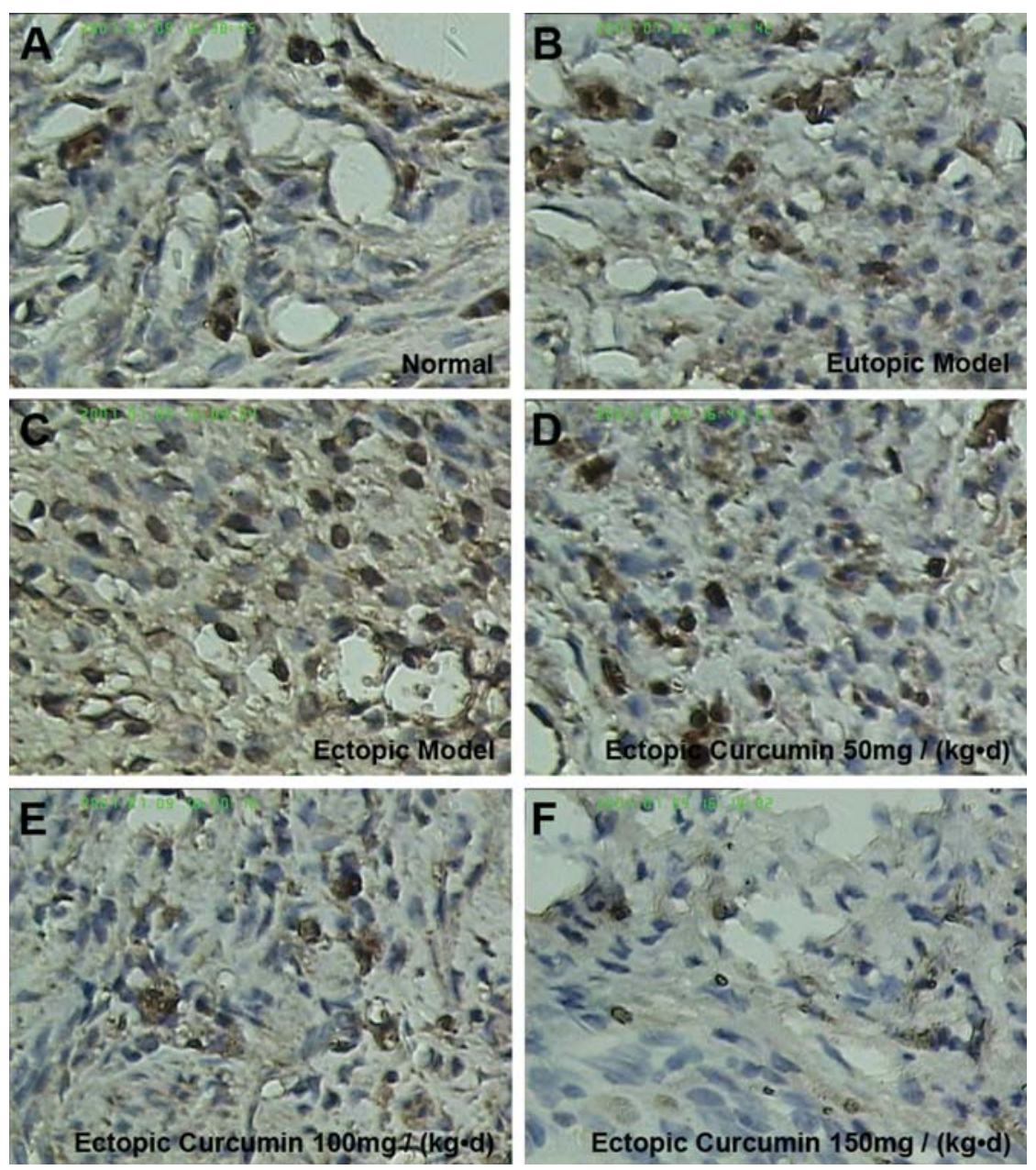

Figure 4. (A) Blood vessels were stained using anti-CD31 antibody. (A and B) MVD in eutopic endometrium of the model group is higher than that in the normal group. (B and C) MVD in ectopic endometrial lesions is significantly higher than that in the eutopic endometrium in the model group. (A, D, E and F) MVD in eutopic endometrium of the curcumin groups $(50,100$, and $150 \mathrm{mg} /(\mathrm{kg} \bullet \mathrm{d})$ and the normal group show no significant differences. (A) Normal group. (B) Eutopic endometrium of the model group. (C) Ectopic endometrium of the model group. Ectopic endometrium of the (D) 50 , (E) 100 and (F) $150 \mathrm{mg} /$ $(\mathrm{kg} \bullet \mathrm{d})$ curcumin-treated groups $(\mathrm{A}-\mathrm{F}: \mathrm{CD} 31, \mathrm{x} 100)$.

endometrium in the model group; however, the MVD of the eutopic endometrium in the model group was not significantly different $(\mathrm{P}>0.05)$ from the normal or sham group. After curcumin treatment, the MVD of the eutopic endometrium in the low-dose group, middle-dose group, high-dose group and normal group showed no significant differences $(\mathrm{P}>0.05)$ (Table III, Fig. 4).
Expression of VEGF protein in the eutopic and ectopic endometrium. The endometrium of the normal rats and the eutopic and ectopic endometrium of the model group showed VEGF protein expression. The eutopic and ectopic endometrium expression of VEGF protein in the model rat group was higher than that in the normal group, and expression of VEGF protein in the ectopic endometrium of the model group 


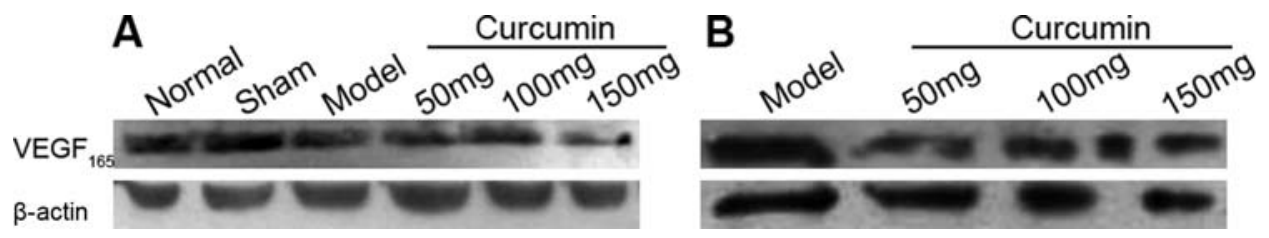

Figure 5. The normal rat endometrium and the model rat group eutopic and ectopic endometrium exhibit VEGF protein expression. Expression of VEGF protein in both the eutopic and ectopic endometrium is higher in the model group than in the normal group, and expression is more evident in the ectopic endometrium of the model group than in the normal group $(\mathrm{P}<0.05)$. VEGF protein expression in the ectopic endometrium of the EMS rats is also higher than that in the eutopic endometrium. After curcumin treatment, VEGF protein expression of the ectopic endometrium was decreased with increasing doses of curcumin $(\mathrm{P}<0.05)$. (A) Eutopic endometrial expression of VEGF protein in each group. (B) Ectopic endometrial expression of VEGF protein in each group.

Table IV. Eutopic and ectopic endometrial expression of VEGF protein in each rat group.

VEGF protein expression in

Eutopic endometrium

Ectopic endometrium

Normal group
Sham group
Model group
Curcumin $50 \mathrm{mg} /(\mathrm{kg} \cdot \mathrm{d})$ group
Curcumin $100 \mathrm{mg} /(\mathrm{kg} \bullet \mathrm{d})$ group
Curcumin $150 \mathrm{mg} /(\mathrm{kg} \bullet \mathrm{d})$ group

$0.621 \pm 0.137$

$0.636 \pm 0.110$

$0.664 \pm 0.129$

$1.246 \pm 0.198$

$0.645 \pm 0.091$

$0.955 \pm 0.303^{\mathrm{a}}$

$0.600 \pm 0.110$

$0.904 \pm 0.222^{\mathrm{b}}$

$0.626 \pm 0.121$

$0.891 \pm 0.268^{\mathrm{b}}$

Compared with the model group, ${ }^{\mathrm{a}} \mathrm{P}<0.05,{ }^{\mathrm{b}} \mathrm{P}<0.01$. Values are presented as the mean $\pm \mathrm{SD}$.

was more obvious $(\mathrm{P}<0.05)$. VEGF protein expression of EMS in the rat ectopic endometrium was also higher than that in the eutopic endometrium. After curcumin treatment, VEGF protein expression in the ectopic endometrium was decreased with increasing doses of curcumin $(\mathrm{P}<0.05)$ (Table IV, Fig. 5).

Relationship between MVD and VEGF protein expression in each group. MVD and VEGF expression in eutopic endometrium had a correlation coefficient of $\mathrm{r}=0.406(\mathrm{P}=0.00691)$ for all 6 groups. MVD and VEGF expression in ectopic endometrium had a correlation coefficient $\mathrm{r}=0.364(\mathrm{P}=0.048)$. This indicated a positive correlation between indicators.

\section{Discussion}

The main method of establishing EMS is through surgical transplantation of endometrial tissue or other cells either subcutaneously or intraperitoneally. Our study modified the modeling approach of Haber et al (15). We selected adolescent rats $60 \pm 5$ days old for the modeling as the organization and growth potential of cells are better in adolescent than in adult rats.

EMS is an estrogen-dependent disease (16-18). In the present study, estradiol $0.1 \mathrm{mg} /(\mathrm{kg} \bullet \mathrm{d})$ was administered, and after 10 days of modeling a small mass (the size of a grain of rice) in the rat abdominal cavity was felt. This also confirmed that low-dose estrogen was sufficient to stimulate the growth of the graft and promote the secretion of various angiogenic factors increasing the local blood supply to the pelvic region, which increased the supply of nutrients to promote better growth of the ectopic endometrium.

The classic method for modeling EMS in rats involves the surgical transplantation of autologous endometria into parts of the abdomen such as the suture on the abdominal wall, ovarian surface, Douglas cavity or other body parts. In the present study, the transplant was placed between the abdominal and subcutaneous fascia. Compared with the classic transplantation, this method ensures that the endometrium is fixed and difficult to move, which helps its growth and survival. In addition, the operation is simple, eliminating the trouble of surgical suture, and provides a short operative time. Ectopic endometrium can be observed and measured without open surgery, which can extend the experimental period and facilitate the continuity of repeated experiments and observational studies. Preoperative use of estrogen, synchronization of the estrus cycle of the rats, and excluding non-estrus and estrus in the surgical outcomes help to improve the success rate of the modeling.

The concept of angiogenesis was first proposed and used by Hertig in 1935, and angiogenesis has been found to be involved in different pathological processes, such as inflammation, wound healing, immune response, tumors and EMS (19). EMS involves benign lesions, yet some of its biological behaviors, such as unlimited growth, reduction in the number of apoptotic cells and angiogenesis, is similar to malignant tumors. The most striking feature is tissue invasion and blood vessel formation. Based on Sampson's theory of endometrial implantation (20), establishment and maintenance of the surrounding tissue blood supply are basic conditions 
ensuring the survival of ectopic endometrial implantation and EMS. Many studies have confirmed that EMS and angiogenesis are closely related $(4-8,21)$.

Microvessel density (MVD) is a quantitative description of angiogenesis. CD31 or platelet endothelial cell adhesion molecule-1 (PECAM-1) is a transmembrane glycoprotein with a molecular weight of $130 \mathrm{kDa}$ found mainly in endothelial cells and leukocytes, which participates in angiogenesis as an endothelial cell-specific marker. In this study, blood vessels were indicated using anti-CD31 antibody and it was found that the MVD of ectopic endometrial lesions was significantly higher compared to that of eutopic endometrium in the model group $(25.51 \pm 8.85$ and $19.93 \pm 4.51$, respectively). Since the sample size was small, MVD of the ectopic endometrial and eutopic endometrium was not analyzed, but the results are similar to those reported by Schindl et al (22) and Khan et al (23) confirming the appearance of lesions and maintaining close correlation with the local blood supply. We speculated that ectopic lesions promote secretion of angiogenesis-related factors, such as vascular endothelial growth factor (VEGF), and this stimulates vascular endothelial cell proliferation and migration, providing a rich blood supply for the ectopic endometrium and the basis for the existence of lesions and their continued growth (24).

Similar to a report by Bourlev et al (25), the present study found that MVD of eutopic endometrium was higher in the model group than that in the normal group $(19.93 \pm 4.51$ and $17.54 \pm 2.35$, respectively). This is consistent with pathological characteristics of human EMS due to the presence of ectopic lesions that cause the eutopic state of EMS to have high proliferation and increased local MVD. Eutopic and ectopic endometrium may exist heterogeneously, which may have resulted in the eutopic endometrium of the model group to have higher than normal MVD. In this study, there was no significant difference in MVD between the endometria of the animals in the normal group and the sham group. This indicates that surgical intervention is certainly a cause of abdominal adhesion by stimulating local immunity; however, laparotomy of rat endometrium has little effect on proliferation and metabolism.

VEGF is a glycoprotein dimer first isolated from bovine pituitary astrocytes in culture medium by Ferrara and Henzel (26) in 1989. The relative molecular weight of VEGF is 34$45 \mathrm{kDa}$. The human VEGF gene is a single gene, and gene transcription of VEGF mRNA can occur in five different ways, producing five different forms, namely, $\mathrm{VEGF}_{121}$, $\mathrm{VEGF}_{145}, \mathrm{VEGF}_{165}, \mathrm{VEGF}_{189}$ and $\mathrm{VEGF}_{206}$. The molecular biology and structural characteristics of the five VEGFs are also different. $\mathrm{VEGF}_{165}$ expression is the most abundant and $\mathrm{VEGF}_{121}$ plays a leading role in the growth of blood vessels. Our results show that ectopic endometrium has a high level of protein expression of $\mathrm{VEGF}_{165}$ in EMS rats, but $\mathrm{VEGF}_{121}$ was not detected. This may be because $\mathrm{VEGF}_{165}$ has a larger molecular weight and is expressed more widely. $\mathrm{VEGF}_{121}$ plays the largest role in angiogenesis; however, its molecular weight is smaller and detection of the protein is difficult. Thus, VEGF $_{121}$ may not have been detected in the present study.

VEGF plays important roles as an endothelial cell-specific mitogen in physiological and pathological angiogenesis.
Studies confirm that VEGF, mainly in ectopic lesions and peritoneal fluid in EMS patients, activates macrophages as its main source (27). Khan et al (23) found that patients with endometriosis of peritoneal red lesions had significantly increased VEGF. Na et al (28) found that VEGF levels were increased in patients indicating angiogenesis in a more active state, leading to pelvic congestion which is related to clinical chronic pelvic pain, menorrhagia, extended period of menstruation and other clinical symptoms. Tan et al (24), using RT-PCR, measured the eutopic and ectopic endometrial expression of VEGF mRNA and found that VEGF mRNA expression in ectopic lesions was significantly increased when compared to that in eutopic tissue. Mclaren et al (29) measured VEGF in the peritoneal fluid of EMS patients and normal women and found that VEGF concentrations in EMS were significantly higher than those in normal women; peritoneal fluid receded into the abdominal cavity of the endometrium by counter-current and secreted more VEGF because of hypoxia. This study found that ectopic endometrium of EMS rats had high levels of $\mathrm{VEGF}_{165}$ protein expression. In addition, the local MVD value and $\mathrm{VEGF}_{165}$ protein expression had a significant positive correlation, suggesting that VEGF in EMS may aid local ectopic endometrium by VEGF-mediated angiogenesis to obtain the necessary nutrients to survive.

Curcumin is a plant polyphenol extracted from the traditional Chinese medicine turmeric. In recent years, studies have focused on the ability of curcumin to inhibit the growth of multiple tumor areas (11-14). EMS is similar to cancer as it is characterized by excessive formation of blood vessels (30). In the present study, we selected curcumin as a therapeutic intervention for EMS since a study utilizing a drug component can rule out many ingredients that do not determine the onset of specific components of a state. Curcumin has low solubility in water and does not melt in ether or chloroform, but can melt in methanol, ethanol, dimethyl sulfoxide and other organic solvents. Organic solvents exhibit toxicity in experimental animals, so the commonly used clinical pharmaceutical excipient is carboxymethyl cellulose because it has good absorbency, is nontoxic, has non-immunogenicity and has good biocompatibility (31). Therefore, we used $0.5 \%$ carboxymethyl cellulose sodium solution to make curcumin into a suspension for oral administration to rats.

Laboratory animals were observed before and after treatment and showed no significant differences in activity level or food consumption and no significant changes in body weight indicating the drug safety and absence of side effects of curcumin, consistent with reported results $(32,33)$. This study found that increasing doses of curcumin gradually reduced implantation size $(87.71 \pm 80.23,60.56 \pm 55.21$, $31.98 \pm 32.18$, respectively), and the number of new blood vessels was significantly reduced in ectopic tissue. This indicates that in the rat model of EMS, eutopic and ectopic endometrium exhibited different responses to curcumin in regards to angiogenesis, which may be due to the heterogeneity between eutopic and ectopic endometrium. Curcumin inhibits ectopic endometrium angiogenesis through inhibition of the secretion of pro-angiogenic factors in a dosedependent manner and mitigates or prevents the occurrence 
and development of EMS. In this study, VEGF expression in ectopic endometrial tissue decreased with increasing curcumin concentration, and MVD and VEGF in ectopic endometrial tissue of the treated groups were positively correlated (correlation coefficient of ectopic endometrial $r=0.364$, $\mathrm{P}=0.048$ ). This may be because curcumin inhibits ectopic tissue angiogenesis by inhibiting expression of VEGF thus narrowing the endometriotic lesion so that the graft undergoes atrophy.

In conclusion, heterogeneity exists between eutopic and ectopic endometrium due to MVD, and VEGF expression in the eutopic endometrium of the model group was not similar to that in the ectopic endometrium. Curcumin was found to decrease the quantity of microvessels and VEGF protein expression in the heterotopic endometrium of EMS rats. Thus, curcumin has potential applications for the treatment of endometriosis.

\section{Acknowledgements}

This research was supported by the Department of Education of Hubei Province (grant no. B20092405).

\section{References}

1. Garcia Manero M, Olartecoechea B, Royo Manero P, Auba M and Lopez G: [Endometriosis]. Rev Med Univ Navarra 53: 4-7, 2009.

2. Cramer DW and Missmer SA: The epidemiology of endometriosis. Ann NY Acad Sci 955: 11-22, 2002.

3. The Practice Committee of the American Society for Reproductive Medicine: Endometriosis and infertility. Fertil Steril 81: 1441-1446, 2004.

4. Abulafia $\mathrm{O}$ and Sherer DM: Angiogenesis of the endometrium. Obstet Gynecol 94: 148-153, 1999.

5. Laschke MW and Menger MD: In vitro and in vivo approaches to study angiogenesis in the pathophysiology and therapy of endometriosis. Hum Reprod Update 13: 331-342, 2007.

6. Taylor RN, Yu J, Torres PB, Schickedanz AC, Park JK, Mueller MD and Sidell N: Mechanistic and therapeutic implications of angiogenesis in endometriosis. Reprod Sci 16: 140-146, 2009.

7. McLaren J: Vascular endothelial growth factor and endometriotic angiogenesis. Hum Reprod Update 6: 45-55, 2000.

8. Goteri G, Lucarini G, Filosa A, et al: Immunohistochemical analysis of vascular endothelial growth factor cellular expression in ovarian endometriomata. Fertil Steril 81: 1528-1533, 2004.

9. Flower A, Lewith GT and Little P: Seeking an oracle: using the Delphi process to develop practice guidelines for the treatment of endometriosis with Chinese herbal medicine. J Altern Complement Med 13: 969-976, 2007.

10. Wieser F, Cohen M, Gaeddert A, Yu J, Burks-Wicks C, Berga SL and Taylor RN: Evolution of medical treatment for endometriosis: back to the roots? Hum Reprod Update 13: 487-499, 2007.

11. Lin YG, Kunnumakkara AB, Nair A, et al: Curcumin inhibits tumor growth and angiogenesis in ovarian carcinoma by targeting the nuclear factor-kappaB pathway. Clin Cancer Res 13: 3423-3430, 2007.

12. Bhattacharyya S, Mandal D, Sen GS, et al: Tumor-induced oxidative stress perturbs nuclear factor-kappaB activityaugmenting tumor necrosis factor-alpha-mediated T-cell death: protection by curcumin. Cancer Res 67: 362-370, 2007.

13. Perry MC, Demeule M, Regina A, Moumdjian R and Beliveau R: Curcumin inhibits tumor growth and angiogenesis in glioblastoma xenografts. Mol Nutr Food Res 58: 1192-1201, 2010.
14. Yoysungnoen $\mathrm{P}$, Wirachwong $\mathrm{P}$, Bhattarakosol $\mathrm{P}$, Niimi $\mathrm{H}$ and Patumraj S: Effects of curcumin on tumor angiogenesis and biomarkers, COX-2 and VEGF, in hepatocellular carcinoma cell-implanted nude mice. Clin Hemorheol Microcirc 34: 109-115, 2006.

15. Haber E, Danenberg HD, Koroukhov N, Ron-El R, Golomb G and Schachter M: Peritoneal macrophage depletion by liposomal bisphosphonate attenuates endometriosis in the rat model. Hum Reprod 24: 398-407, 2009.

16. Dizerega GS, Barber DL and Hodgen GD: Endometriosis: role of ovarian steroids in initiation, maintenance, and suppression. Fertil Steril 33: 649-653, 1980.

17. Zeitoun K, Takayama K, Sasano H, et al: Deficient 17betahydroxysteroid dehydrogenase type 2 expression in endometriosis: failure to metabolize 17beta-estradiol. J Clin Endocrinol Metab 83: 4474-4480, 1998.

18. Hong $\mathrm{M}$ and Zhu Q: Macrophages are activated by 17betaestradiol: possible permission role in endometriosis. Exp Toxicol Pathol 55: 385-391, 2004.

19. Carmeliet P and Jain RK: Angiogenesis in cancer and other diseases. Nature 407: 249-257, 2000.

20. Sampson JA: Metastatic or embolic endometriosis, due to the menstrual dissemination of endometrial tissue into the venous circulation. Am J Pathol 3: 93-110 143, 1927.

21. Smith SK: Angiogenesis. Semin Reprod Endocrinol 15: 221-227, 1997.

22. Schindl M, Birner P, Obermair A, Kiesel L and Wenzl R: Increased microvessel density in adenomyosis uteri. Fertil Steril 75: 131-135, 2001.

23. Khan KN, Masuzaki H and Fujishita A: Imunoexpression of hepatocyte growth factor and c-Met receptor in the eutopic endometrium predicts the activity of ectopic endometrium. Fertil Steril 79: 173-181, 2003.

24. Tan XJ, Lang JH, Liu DY, Shen K, Leng JH and Zhu L: Expression of vascular endothelial growth factor and thrombospondin-1 mRNA in patients with endometriosis. Fertil Steril 78: 148-153, 2002.

25. Bourlev V, Volkov N, Pavlovitch S, Lets N, Larsson A and Olovsson M: The relationship between microvessel density, proliferative activity and expression of vascular endothelial growth factor-A and its receptors in eutopic endometrium and endometriotic lesions. Reproduction 132: 501-509, 2006.

26. Ferrara N and Henzel WJ: Pituitary follicular cells secrete a novel heparin-binding growth factor specific for vascular endothelial cells. Biochem Biophys Res Commun 161: 851-858, 1989.

27. Mahnke JL, Dawood MY and Huang JC: Vascular endothelial growth factor and interleukin-6 in peritoneal fluid of women with endometriosis. Fertil Steril 73: 166-170, 2000.

28. Na YJ, Yang SH, Baek DW, et al: Effects of peritoneal fluid from endometriosis patients on the release of vascular endothelial growth factor by neutrophils and monocytes. Hum Reprod 21: 1846-1855, 2006.

29. McLaren J, Prentice A, Charnock-Jones DS, Millican SA, Muller KH, Sharkey AM and Smith SK: Vascular endothelial growth factor is produced by peritoneal fluid macrophages in endometriosis and is regulated by ovarian steroids. J Clin Invest 98: 482-489, 1996.

30. Machado DE, Abrao MS, Berardo PT, Takiya CM and Nasciutti LE: Vascular density and distribution of vascular endothelial growth factor (VEGF) and its receptor VEGFR-2 (Flk-1) are significantly higher in patients with deeply infiltrating endo-metriosis affecting the rectum. Fertil Steril 90: 148-155, 2008.

31. Burns JW, Skinner K, Colt J, Sheidlin A, Bronson R, Yaacobi Y and Goldberg EP: Prevention of tissue injury and postsurgical adhesions by precoating tissues with hyaluronic acid solutions. $\mathrm{J}$ Surg Res 59: 644-652, 1995.

32. Sharma RA, Euden SA, Platton SL, et al: Phase I clinical trial of oral curcumin: biomarkers of systemic activity and compliance. Clin Cancer Res 10: 6847-6854, 2004.

33. Cheng AL, Hsu CH, Lin JK, et al: Phase I clinical trial of curcumin, a chemopreventive agent, in patients with high-risk or pre-malignant lesions. Anticancer Res 21: 2895-2900, 2001. 